\title{
Modulation of Illusory Reversal in Tactile Temporal Order by the Phase of Posterior $\alpha$ Rhythm
}

\author{
(DToshimitsu Takahashi ${ }^{1,2}$ and Shigeru Kitazawa ${ }^{1,2,3}$ \\ ${ }^{1}$ Dynamic Brain Network Laboratory, Graduate School of Frontier Biosciences, Osaka University, Osaka, 565-0871, Japan, ${ }^{2}$ Department of Brain Physiology, \\ Graduate School of Medicine, Osaka University, Osaka, 565-0871 Japan, and ${ }^{3}$ Center for Information and Neural Networks, National Institute of \\ Information and Communications Technology, and Osaka University, Osaka, 565-0871, Japan
}

The subjective temporal order of tactile stimuli, delivered sequentially to each hand with an interval of $100-300 \mathrm{~ms}$, is often inverted when the arms are crossed. Based on data from behavioral and neuroimaging studies, it has been proposed that the reversal is due to a conflict between anatomical and spatial representations of the tactile signal or to the production of an inverted apparent motion signal. Because the $\alpha$ rhythms, which consist of a few distinct components, reportedly modulate tactile perception and apparent motion and serve as a $10 \mathrm{~Hz}$ timer, we hypothesized that the illusory reversal would be regulated by some of the $\alpha$ rhythms. To test this hypothesis, we conducted magnetoencephalographic recordings in both male and female participants during the tactile temporal order judgment task. We decomposed the $\alpha$ rhythms into five independent components and discovered that the illusory reversal was modulated by the phase of one independent component with strong current sources near the parieto-occipital (PO) sulcus (peri-P0 component). As expected, the estimated current sources distributed over the human MST implicated to represent tactile apparent motion, in addition to the intraparietal region implicated in mapping tactile signals in space. However, the strongest source was located in the precuneus that occupies a central hub region in the cortical networks and receives tactile inputs through a tecto-thalamic pathway. These results suggest that the peri-PO component plays an essential role in regulating tactile temporal perception by modulating the thalamic nuclei that interconnect the superior colliculus with the cortical networks.

Key words: $\alpha$ rhythm; arm crossing; independent component analysis; MEG; $\mu$ rhythm; temporal order judgment

\section{Significance Statement}

Despite a long-held hypothesis that the posterior $\alpha$ rhythm serves as a $10 \mathrm{~Hz}$ timer that regulates human temporal perception, the contribution of the $\alpha$ rhythms in temporal perception is still unclear. We examined how the $\alpha$ rhythms influence tactile temporal order judgment. Judgment reversal depended on the phase of one particular $\alpha$ rhythm with its source near the parieto-occipital sulcus. The peri-parieto-occipital $\alpha$ rhythm may play a crucial role in organizing tactile temporal perception.

\section{Introduction}

The subjective temporal order of tactile stimuli, delivered one to each hand with an interval of $100-300 \mathrm{~ms}$, is often inverted when the arms are crossed but not when they are uncrossed (Yamamoto

\footnotetext{
Received Aug. 1, 2015; revised April 11, 2017; accepted April 21, 2017.

Author contributions: T.T. and S.K. designed research; T.T. and S.K. performed research; T.T. and S.K. analyzed data; T.T. and S.K. wrote the paper.

This work was supported by Grants-in-Aid for Scientific Research on Innovative Areas 25119002 and (A) 25240022 to S.K. We thank Tamami Nakano for comments on the manuscript; Keisuke Toyama, Kenji Kansaku, and Makoto Wada for discussions during the exploratory phase of the study; Masayuki Hirata, Takufumi Yanagisawa, Masayuki Mochizuki, and Eiichi Okumura for advice on MEG measurements and analyses; and Yoshiyuki Watanabe and Hisashi Tanaka for support in the MRI experiments.

The authors declare no competing financial interests.

Correspondence should be addressed to Dr. Shigeru Kitazawa, Dynamic Brain Network Laboratory, Graduate School of Frontier Biosciences, Osaka University, 1-3 Yamadaoka, Suita, Osaka 565-0871, Japan. E-mail: kitazawa@fbs.osaka-u.ac.jp.

DOI:10.1523/JNEUROSCI.2899-15.2017

Copyright $\odot 2017$ the authors $\quad 0270-6474 / 17 / 375298-11 \$ 15.00 / 0$
}

and Kitazawa, 2001; Shore et al., 2002; Heed and Azañón, 2014). Although a number of accounts have been proposed since the first report of the illusion (Yamamoto and Kitazawa, 2001; Shore et al., 2002; Kitazawa et al., 2007; Badde et al., 2014), all accounts refer to the transformation of tactile signals between somatotopic (anatomical) and external spatial maps (for review, see Heed and Azañón, 2014). For example, it has been hypothesized that the reversal occurs due to fast erroneous mapping of the tactile signal to the wrong hand (Fig. 1, 1' and 2') (Kitazawa, 2002; Kitazawa et al., 2007).

However, even when the arms are not crossed, tactile temporal order judgment (TOJ) is inverted by presenting incongruent visual stimuli that evoke apparent motion in the opposite direction (Kitazawa et al., 2007). Further, we have shown in our recent neuroimaging study that the human homolog of MT/MST, which has been implicated in representing the apparent motion signal, is also involved in tactile TOJ (Takahashi et al., 2013). 

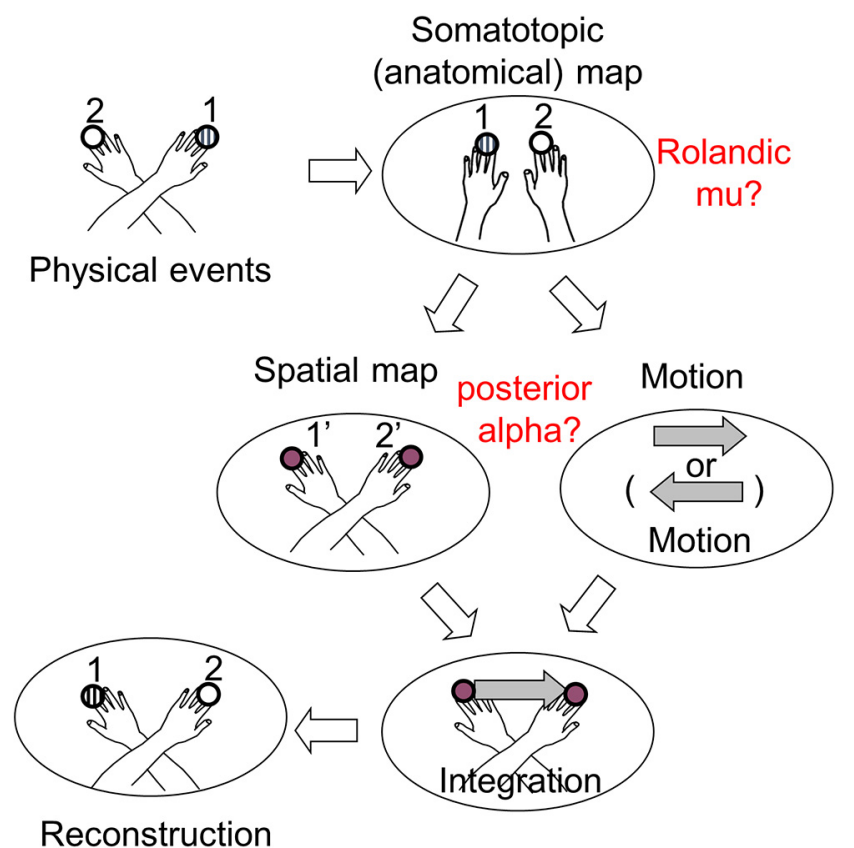

Figure 1. Hypothetical processes underlying illusory reversal of the tactile temporal order due to arm crossing. It has been hypothesized, for example, that the reversal occurs due to a rapid erroneous mapping of the tactile signal to the wrong hand in the spatial map ( $1{ }^{\prime}$ and $2^{\prime}$ ). Others have proposed that the reversal occurs due to a conflict between anatomical and spatial maps (Heed and Azañón, 2014). Based on data from behavioral and neuroimaging studies, we proposed that the production of an inverted apparent motion signal plays an essential role (motion projection hypothesis): subjective temporal order is reconstructed by combining information regarding "what happened where" in the spatial map and information regarding "when" that is captured in a motion vector (Takahashi et al., 2013). In either hypothesis, many opportunities occur for the $\alpha$ rhythms to affect the process of illusory reversal in tactile TOJ. The Rolandic $\mu$ rhythm might affect signal processing in the somatotopic map in the primary sensory cortex, and the posterior $\alpha$ rhythms would affect tactile mapping to the spatial maps, production of apparent motion signals, or the process of integrating distributed information in some hub region in the medial parietal cortex.

Based on these findings, we propose that reversal occurs because of the production of an inverted apparent motion signal (Fig. 1; motion projection hypothesis).

Rhythmic activity at $\sim 10 \mathrm{~Hz}$, the most prominent electrophysiological activity in the human brain (Varela et al., 1981; Hari et al., 1997; Palva and Palva, 2011), consists of three physiologically independent components (ICs): the posterior $\alpha$, the Rolandic $\mu$, and the midtemporal tau rhythms (Hari et al., 1997; Niedermeyer, 1997; Pineda, 2005). A range of visual perceptions has been shown to correlate with the phase of the posterior $\alpha$ rhythm (Varela et al., 1981; Busch et al., 2009; Mathewson et al., 2009; Dugué et al., 2011; Sokoliuk and VanRullen, 2013). In a pioneering study in 1981, Varela et al. (1981) reported that the perception of two successive visual stimuli with an interval of $\sim 70$ ms was altered from simultaneity to discontinuity via apparent motion, depending on the phase of the posterior $\alpha$ rhythm (Varela et al., 1981). It was also proposed that the posterior $\alpha$ rhythm serves as a $10 \mathrm{~Hz}$ timer that regulates temporal perception (Kristofferson, 1967). Assuming that the posterior $\alpha$ rhythm modulates visual apparent motion, our motion projection hypothesis predicts that the illusory reversal is also modulated by the posterior $\alpha$ rhythm (Fig. 1).

Recent studies have also shown that tactile attention in the external hemispace can be modulated by the posterior $\alpha$ rhythm (Schubert et al., 2015) or by transcranial $\alpha$ stimulation of the parietal cortex (Ruzzoli and Soto-Faraco, 2014). Thus, the judg- ment may also be altered through the direct effects of the posterior $\alpha$ rhythm on either the tactile perception or the process of localizing each individual tactile stimulus in the external space (Kitazawa, 2002; Heed and Azañón, 2014; Heed et al., 2015).

However, the threshold for tactile perception has been shown to negatively correlate with the power of the $\mu$ rhythm (Jones et al., 2010; van Ede et al., 2011). Further, the $\mu$ rhythm was once hypothesized to entrain the visual, auditory, and somatosensorycentered $\alpha$ networks (Pineda, 2005). Thus, tactile TOJ may also be affected by the phase of the Rolandic $\mu$ rhythm (Fig. 1).

In the current study, we tested whether the illusory reversal would be regulated by any of the $\alpha$ rhythms. To test this hypothesis, we decomposed the $\alpha$-band signals into five ICs and compared the phase and the power of each independent $\alpha$-band component between trials with correct judgment and those with inverted judgment. We show that the probability of illusory reversal is modulated by the phase of the posterior $\alpha$ rhythm that has its major current sources around the parieto-occipital (PO) sulcus but not with any other $\alpha$-band components, including the $\mu$ or the $\tau$ rhythms.

\section{Materials and Methods}

Participants. Forty-seven right-handed healthy volunteers (38 males and 9 females, ranging in age from 20 to 49 years) participated in the behavioral experiments for screening, and 22 subjects further participated in MEG recordings. No participants had a history of neurological disorders, and all were right-handed (laterality quotient, 80-100) according to the Edinburgh Inventory (Oldfield, 1971). All except for one of the coauthors (T.T.) were naive to the purpose of the experiments. Written informed consent was obtained from all participants before the experiments. The study received approval from the Ethical Review Board of Osaka University, Graduate School of Frontier Biosciences. The study conforms with the World Medical Association Declaration of Helsinki.

\section{Experimental design and statistical analysis}

Behavioral experiments. The screening experiments were conducted to choose participants who showed reversal of tactile TOJ with a probability greater than a threshold of 0.45 (45\% incorrect) at an optimal stimulus onset asynchrony (SOA). This threshold was set to exclude the bottomhalf participants who showed a smaller probability of judgment reversal than the top-half participants (Nishikawa et al., 2015) simply because we needed some trials with inverted judgements during the main experiment in the MEG scanner. The participants sat with their palms facing down on a desk and their arms uncrossed (arms-uncrossed condition) or crossed (arms-crossed condition). Mechanical skin contacts (FR-2007-2; Uchida Denshi) were used to deliver brief tactile stimulation (a single pulse of $10 \mathrm{~ms}$ duration with a strength of $>2$ times the threshold) to the dorsal surface of the ring finger of each hand. The distance between the contacts was fixed at $20 \mathrm{~cm}$ in both conditions. Push buttons for responses were placed under the index fingers. The participants closed their eyes during the entire experiment and wore earplugs and headphones that delivered white noise. Thus, the participants were not able to see or hear the tactile stimuli (Yamamoto and Kitazawa, 2001).

Two successive tactile stimuli were delivered, one to each hand with an SOA chosen pseudo-randomly from 12 SOAs $(-960,-480,-240$, $-120,-60,-30,30,60,120,240,480$, and $960 \mathrm{~ms}$ for the uncrossed condition; $-1920,-960,-480,-240,-120,-60,60,120,240,480$, 960 , and $1920 \mathrm{~ms}$ for the crossed condition), or to the same hand (either to the right or left hand) in two catch trials per block ( $\mathrm{SOA}=120 \mathrm{~ms}$ for the uncrossed condition and $240 \mathrm{~ms}$ for the crossed condition). Thus, a block consisted of 14 trials. In each trial, participants were required to judge the order of two stimuli and respond by pushing a button under the index finger of the hand that was stimulated second as soon as possible, but only after the second stimulus was delivered. The catch trials were used to prevent participants from making any premature response to the first stimulus. Each subject participated in two experiments (one for each 
condition). Each experiment consisted of eight blocks of 112 trials in total.

Response data were combined for each SOA in each condition. A sigmoid function (e.g., see Fig. $2 b$, black curve) with four parameters (upper and lower asymptotes, temporal resolution, and the point of subjective simultaneity) was fit to the data in the arms-uncrossed condition, and a Gaussian flip model (e.g., see Fig. $2 b, \mathrm{~N}$-shaped red curve) with five additional parameters (two peak flip probabilities, one from the right-hand-first to left-hand-first judgment $\left[A_{r}\right]$ and another in the reverse direction $\left[A_{l}\right]$, a constant error rate $[c]$, a time window of flip $\left[\sigma_{\mathrm{f}}\right]$, and a bias time for the Gaussian flip function) was fit to the data in the arms-crossed condition, the details of which have been published previously (Yamamoto and Kitazawa, 2001; Wada et al., 2004; Nishikawa et al., 2015). To ascertain that the judgment varies at an SOA of $100 \mathrm{~ms}$ in the MEG experiments, we chose those participants with a peak flip probability (see Fig. $2 c, A_{l}$ ) $>0.45$, a time window of flip $\left(\sigma_{\mathrm{f}}\right)>70 \mathrm{~ms}$, and a constant error rate (simple confusion of which hand) $<0.3$. Twenty-two of the 47 participants $(47 \%)$ met the criteria, and 20 subjects participated in the MEG experiment. Seven of the initially excluded participants with a smaller probability of judgment reversal (bottom-reversers) additionally participated in the MEG experiment for comparison.

$M E G$ experiments. MEG recordings were conducted during the tactile TOJ task by using a 160-channel whole-head neuromagnetometer with coaxial gradiometers (PQA-160C, Yokogawa Electric). MEG signals from the 160 sensors were continuously recorded at $1 \mathrm{kHz}$ during the entire experiment. The signals were bandpass $(0.1-200 \mathrm{~Hz})$ and notch $(60 \mathrm{~Hz})$ filtered before storage for later analyses.

Five marker coils were attached to the face before the participants were oriented in a supine position on a bed with their head inside the magnetometer. The participants performed the tactile TOJ task with their arms crossed. To avoid eye movements, the participants looked at a dot projected on a screen in front of them $(33 \mathrm{~cm}$ from the eyes). Two isolated current stimulators (SEM-4201, Nihon Koden) were used to deliver a square current pulse ( $0.1 \mathrm{~ms}$ in duration, twice the threshold intensity) to the ring finger of each hand. The SOAs were chosen randomly from two conditions: $100 \mathrm{~ms}$ (right-then-left stimulation, RL) or $-100 \mathrm{~ms}$ (leftthen-right stimulation, LR). In addition, two stimuli were delivered to the same hand in $10 \%$ (10 participants) or $50 \%$ (12 participants) of the trials with an SOA of $100 \mathrm{~ms}$ (catch trials). The participants responded by raising the index finger of the hand that they judged as being stimulated second. The position of the index finger was monitored by a photosensor (FS-T20, Keyence).

Each trial was voluntarily started by the participant by resting (setting) their index finger on a photosensor in response to a visual instruction (see Fig. $2 a, \mathrm{SET})$. Then a red dot $\left(0.3^{\circ}\right.$ in visual angle) appeared in the center of the screen on which the participant was requested to fixate without blinking until the end of their response. After a random delay $(1800-2800 \mathrm{~ms})$, two tactile stimuli were delivered, and the participants waited for 1000-1500 ms until the color of the dot changed from red to blue (see Fig. $2 a$, Go signal), which indicated that the participants should make a fast response by raising an index finger. The dot was then replaced with the "SET" instruction, which indicated that participants should prepare for the next trial. The participants were allowed to rest, blink, or make eye movements as long as they liked at this stage, but they had to maintain the index finger in a raised position. When they felt ready, they returned the index finger to the photosensor. Seven par- ticipants completed $100 \mathrm{RL}, 100 \mathrm{LR}$, and 200 catch trials, and 13 participants completed $180 \mathrm{RL}, 180 \mathrm{LR}$, and 40 catch trials.

Structural images for each participant were collected using a T1weighted 3-D SPGR sequence on a 3 tesla whole-body scanner (Discovery MR750w, GE Medical Systems; repetition time $=9.1 \mathrm{~ms}$, echo time $=2.7 \mathrm{~ms}$, flip angle $=15^{\circ}$, field of view $240 \times 240 \mathrm{~mm}$, resolution $1 \times 1 \times 1 \mathrm{~mm}$ ).

Data preprocessing. Data from 4 of the 20 participants were excluded from further analyses; two showed limited judgment reversal in the neuromagnetometer $(<10 \%$ in the LR trials), one made premature responses before the go signal, and another showed strong magnetic noise presumably due to magnetization of dental inlays. MEG data from the remaining 16 participants ( 13 males and 3 females) were downsampled to $500 \mathrm{~Hz}$ and segmented into $4 \mathrm{~s}$ blocks, each of which represented brain activity from -1 to $3 \mathrm{~s}$ with respect to the onset of the first stimulus.

Group IC analysis (ICA). To decompose MEG signals into independent $\alpha$ rhythms that are shared across participants, all data segments were combined across the 16 participants for each of the 160 channels to produce a large data matrix $[160$ rows $\times(4 \mathrm{~s} \times 500 \mathrm{~Hz} \times 6400$ trials $)$ columns]. The data matrix was decomposed into ICs using a fast fixedpoint algorithm implemented in the FastICA MATLAB program (The MathWorks) (Hyvarinen and Oja, 1997). ICA was repeatedly applied to the data matrix with six different numbers of $\operatorname{ICs}(8,12,16,24,48$, and 96). ICA was repeated 10 times for each number of components, and the ICs obtained (e.g., $12 \times 10=120 \mathrm{ICs}$ ) were subjected to a cluster analysis (Ward method implemented in the statistics toolbox in MATLAB) to examine the stability of the ICs. If the 12 ICs were stable, 120 ICs must be classified into 12 clusters, each consisting of 10 members. After applying the cluster analysis, we determined that a cluster of ICs was stable when the number of members was 9,10 , or 11 , and the mean Silhouette value within the cluster was $>0.7$. The Silhouette value is 1 when all members of a cluster are identical to each other (best separation) and is -1 in the 
a

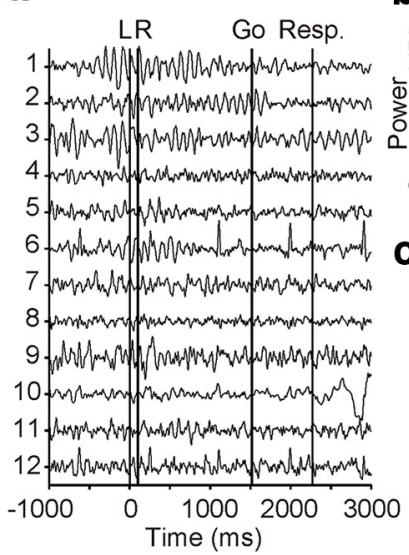

d

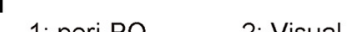

b

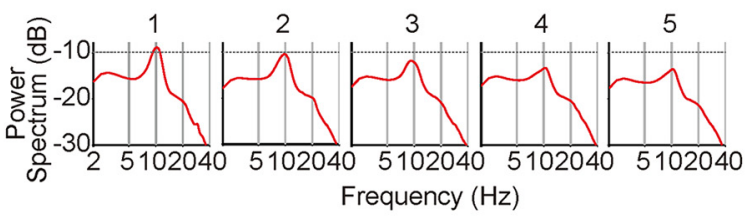

\section{C}
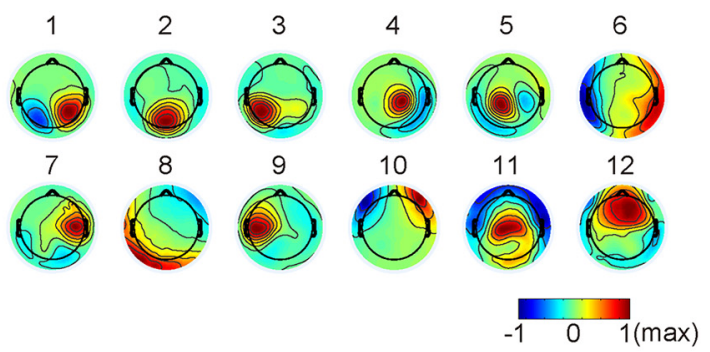

5: Mu-left 4: Mu-right

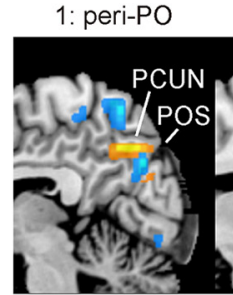

$x=+6$
2: Visual 3: Tau

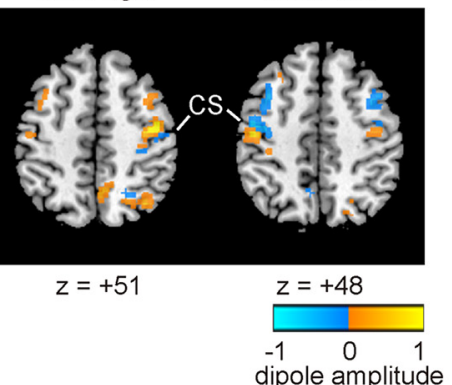

Figure 3. ICs decomposed by the group ICA. The 160 channel MEG data from 16 participants were combined in one data matrix and decomposed into $12 \mathrm{ICS}$. $\boldsymbol{a}$, Example traces of the $12 \mathrm{ICs}$ in one left-then-right stimulation trial (LR) taken from one participant (No. 1). The ICs are numbered in descending order of the $\alpha$ power. $\boldsymbol{b}$, Power spectrum in the top 5 of the $12 \mathrm{ICs}$. A peak is present at $\sim 10 \mathrm{~Hz}$. c, Spatial distribution of the mixing matrix in each of the $12 \mathrm{IC}$. $\boldsymbol{d}$, Current sources estimated for each of the top 5 components. Based on the spatial distributions of the current sources, we termed the 5 components the peri-P0, visual, $\tau, \mu$-right, and $\mu$-left components. PCUN, Precuneus; POS, PO sulcus; A1, primary auditory cortex; CS, central sulcus.

prepared for each participant (individual ICA). The number of ICs varied between 8,12 , and 16 , and we chose the ICs that showed the largest correlation with each of the five ICs defined by the group ICA (e.g., see Fig. $4 a$ ).

Phase comparison. We then examined whether the illusory reversal of the tactile TOJ depended on the phase of the 5 ICs yielded by the individual ICA. Each individual IC was aligned to the stimulation onset of the LR stimulation and grouped according to whether the judgment was correct or inverted. After subtracting the mean event-related signal during a $200 \mathrm{~ms}$ period after the first L stimulus (we used linear tapers with a width of $20 \mathrm{~ms}$ at both ends), we filtered subtracted traces within the band of the $\alpha$ rhythm (7-14 Hz), calculated the instantaneous phase for each trace by using the Hilbert transformation, and compared the distributions of the instantaneous phases between the two judgment groups (inverted/ correct) by using the Watson-Williams test (Berens, 2009) every $10 \mathrm{~ms}$ from -500 to 500 $\mathrm{ms}$ around the onset of the first $\mathrm{L}$ stimulus (see Fig. $4 b$ ). We note two particular procedures. First, we subtracted the mean poststimulus event-related signal during the $200 \mathrm{~ms}$ period because the bandpass filtering of a sharp rise of an event-related signal results in artifactual infiltration of the $\alpha$-band wave backward in time. By subtracting this signal, we prevented this artifactual " $\alpha$-band" wave from obscuring any significant phase difference during the peristimulus period. Second, when applying the Watson-Williams test, we noticed that the test overestimates the difference when the dispersion of the phase becomes larger. We confirmed this tendency by simulation. To avoid this overestimation, we drew two groups of samples, one with the number of the correct trials (e.g., $n=47$ ) and the other with

worst case (Rousseeuw, 1987). With this criterion, the number of stable ICs were 5 of 8,10 of 12, 11 of 16, 19 of 24,35 of 48 , and 65 of 96 .

Each stable IC was then subjected to power spectrum analysis by using a spectopo function implemented in the EEGLAB MATLAB program (Delorme and Makeig, 2004) and ordered according to the power at 10 $\mathrm{Hz}$ because we were interested in the $\alpha$-band signals. Cortical current sources were then estimated for the top 5 ICs by using a multiple sparse prior method implemented in the SPM12 software (Friston et al., 2008). The method is less vulnerable to superficial bias, which is an overemphasis on superficial sources compared with deeper sources, than the classical Minimum Norm and LORETA approaches (López et al., 2014). The estimation was repeated for each cortical surface of the 16 participants by assuming 20,484 current dipoles and 1024 patches of activation. After normalizing the dipole strength by its median value for each participant, estimated dipoles were averaged on a standard MNI template across the 16 participants by using MRIcron software (Rorden et al., 2007).

Because the main purpose of applying the ICA was to objectively separate the $\alpha$-band signals into physiologically ICs, the estimated current sources of the top 5 ICs were compared with current dipoles reported in previous literature for the posterior $\alpha$, the Rolandic $\mu$, and the midtemporal $\tau$ rhythms (Hari et al., 1997; Niedermeyer, 1997; Pineda, 2005). All these physiological components were included in the top 5 ICs, only when 12 ICs were assumed (see Fig. 3). We therefore decided to assume 12 ICs for the group ICA and further defined 5 ICs with physiological relevance in terms of the comparisons with previous studies (see Fig. $3 d$ ).

Individual ICA. The group ICA was adequate to extract typical ICs shared across many participants. However, this process does not guarantee that all participants actually yield the corresponding ICs. In addition, individual differences in the head position in the magnetometer were not taken into account. We thus applied ICA to each of 16 data matrices the number of the inverted trials (e.g., $n=53$ ), from the uniform distribution 10,000 times for each participant and prepared a distribution of the test statistics using the Watson-Williams test. The distribution was used to calculate a $p$ value given the test statistics at each time point.

The resulting time series of $p$ values were transformed to the $Z$ score for each participant and summed over the 16 participants for the secondlevel analysis (see Fig. $4 c$ ). The sum divided by the square root of the number of $Z$ scores (16) was expected to follow the normal distribution under the null hypothesis (Stouffer's method) (Stouffer et al., 1949). The second-level uncorrected $p$ values were further corrected for multiple comparisons $(n=100)$ by using the false discovery rate (FDR) and Bonferroni correction. The same procedures were repeated for the data from the RL trials. The resulting $p$ values in LR and RL trials were further combined using the Stouffer's method.

Amplitude comparison. We used the instantaneous amplitude for each trace obtained by using the Hilbert transformation to compare the distributions of the instantaneous amplitudes between the two judgment groups (inverted/correct) by using the Wilcoxon rank sum test (right or left sided) every $10 \mathrm{~ms}$ from -500 to $500 \mathrm{~ms}$ around the onset of the first stimulus (see Fig. 6b). The $p$ value was transformed to the $Z$ score and summed over the 16 participants for the second-level analyses in the same manner as described for the phase comparison.

Analyses for bottom-reversers. Data from seven additional participants with less judgment reversal (termed here as bottom-reversers) who had been rejected in the initial prescreening were analyzed using the same procedures (preprocessing, ICA, first- and the second-level phase analyses) as those applied to the 16 participants (top-reversers). To compensate for the decrease in statistical power resulting from the paucity of inverted trials ( $23 \%$ vs $42 \%)$ and the decrease in the total number of 
a

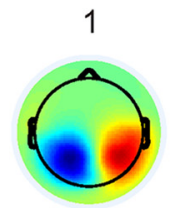

9

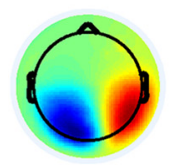

2

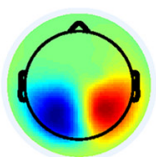

10
3

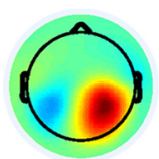

11

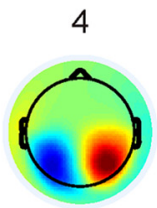

12

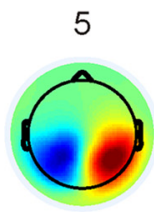

13

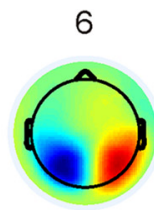

14

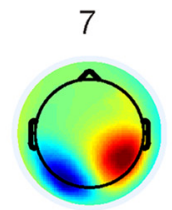

15
8

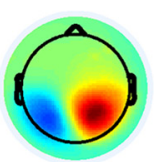

16
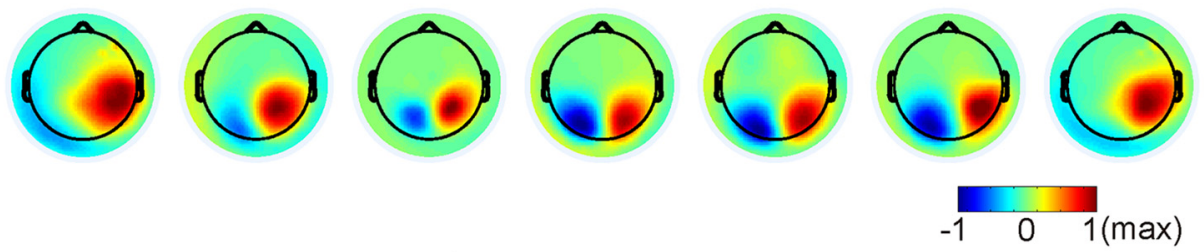

b
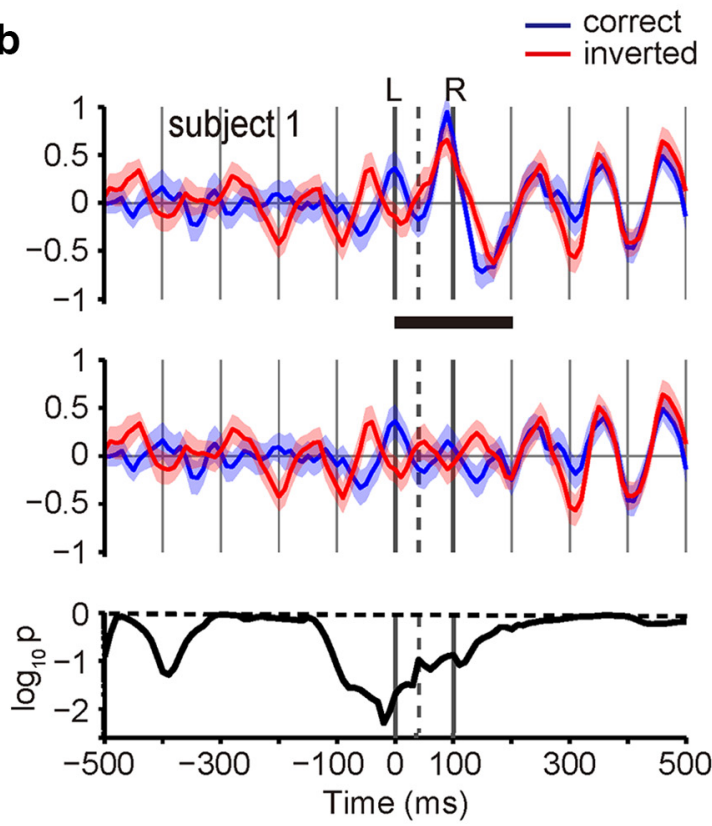

C
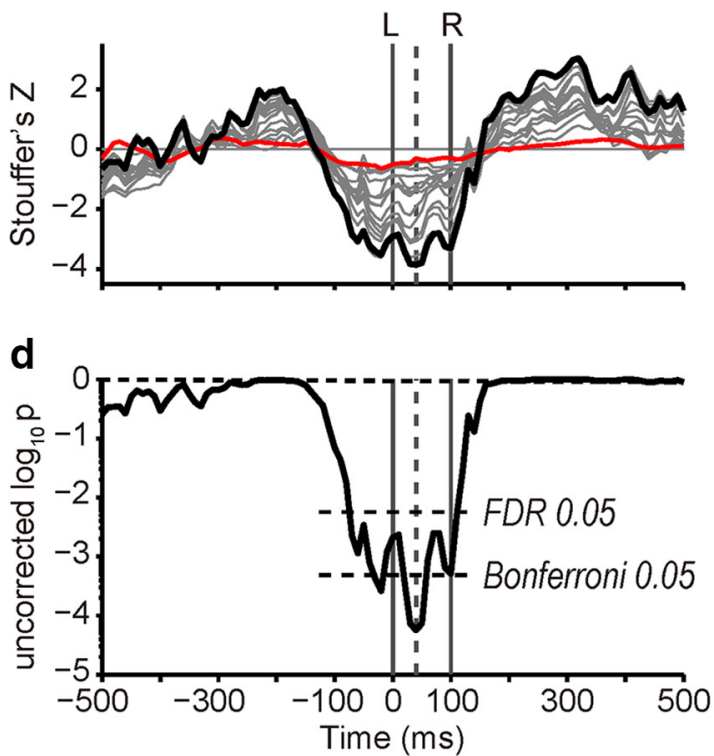

e

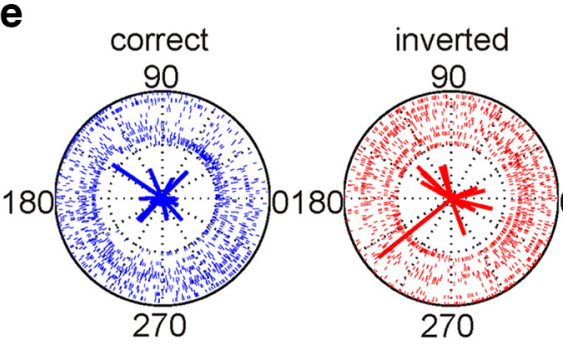

f
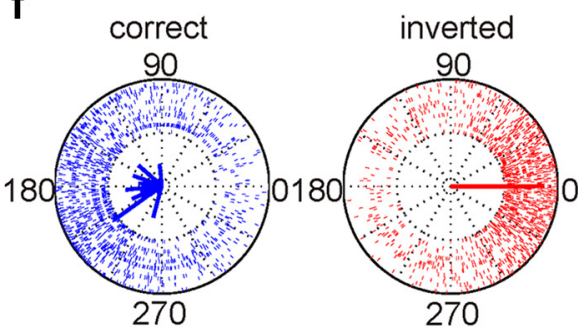

g

Figure 4. Effects of the phase of the peri-PO component on the tactile TOJ. $\boldsymbol{a}$, Spatial distribution of the peri-P0 component in 16 participants; note the similarity across the participants. $\boldsymbol{b}$, Comparison of the peri-P0 component between trials with correct judgment (blue) and those with inverted judgment (red) in individual participants. Top, The mean traces in one typical participant ( $N$ o. 1) in the LR trials ( $n=47$ for correct and 53 for inverted judgment) are shown. Shaded areas represent the SEM. The traces are aligned at the onset of the first $L$ stimulus. Middle, The mean event-related field was subtracted from each trace in the peristimulus period indicated by a horizontal bar $(0-200 \mathrm{~ms})$. Note the obvious difference in the $\alpha$ rhythms in the two traces during the peristimulus period. Bottom, The $p$ values yielded by the Watson-Williams test used to compare the two phase distributions are shown. $\boldsymbol{c}, \boldsymbol{d}$, The second-level analysis. Each uncorrected $p$ value was transformed into a $Z$ score (e.g., a red trace for participant №. 1) and accumulated over the 16 participants (c). The intervals of the gray traces show the contributions from individual participants. The $p$ values yielded from the combined Stouffer's $Z$ score are plotted against the time from the first stimulus $(\boldsymbol{d})$. The phase difference was significant during the peristimulus period after correction for the FDR $(<0.05)$ and the Bonferroni correction. Vertical broken line indicates the timing that yielded the smallest $p$ value $(40 \mathrm{~ms}) . \boldsymbol{e}, \boldsymbol{f}$, Distribution of the mean preferred phase in the correct and inverted judgment trials at the time of the smallest $p$ value ( $40 \mathrm{~ms}$ ). To compensate for the difference in the number of correct and inverted trials, bootstrap samples were drawn 100 times for each trial group (correct/inverted) for each participant, and the 100 mean phases were plotted on each of 16 annuli (No. 1-16, from outside to inside). Middle bars represent the instantaneous mean phase and the mean amplitude. It is apparent that the absolute preferred phase was not shared across participants. $\boldsymbol{b}$ - $\boldsymbol{d}$, Vertical broken line indicates $40 \mathrm{~ms}$, when the smallest $p$ value was observed based on the data from all participants. $\boldsymbol{e}$, When the mean preferred phase in the inverted trials was aligned to zero in every participant, the mean phase in the correct trials was clearly distributed around the opposite direction $(\boldsymbol{f})$. $\boldsymbol{g}$, The mean correct response rate was polar-plotted against the phase of the peri-P0 component. The mean preferred phase was set to zero in every participant. Error bars indicate the SEM across the 16 participants. Post hoc tests of one-way ANOVA (Ryan's method) showed that the mean was significantly different in six pairwise comparisons $(0-180,0-150,330-150,330-180,330-210,60-150, p<0.001)$. 
participants ( $7 \mathrm{vs} 16$ ), we additionally applied a bootstrapping technique. We repeatedly and randomly drew one of the bottom-reversers for each of the 16 top-reversers. Then, we repeatedly drew one trial with correct judgment (or inverted judgment) from the chosen bottom-reverser for each correct (or inverted) judgment trial of the top-reverser.

\section{Results}

Reversal of subjective temporal order due to arm crossing Participants were required to judge the order of successive tactile stimuli that were delivered once to each hand (Fig. 2a). During the screening experiments, participants were able to judge the order perfectly with a SOA of $120 \mathrm{~ms}$, as long as the arms were not crossed (Fig. $2 b$, black). In marked contrast, when the arms were crossed, the participants inverted their judgment, with SOAs between -120 and $120 \mathrm{~ms}$, yielding an $\mathrm{N}$-shaped response curve (Fig. 2b, red). The illusory reversal in tactile TOJ was enhanced by preselection of top-half participants with a peak reversal probability (Fig. $2 c, A_{l}$ ) $>0.45$ but was essentially consistent with previous reports (Yamamoto and Kitazawa, 2001; Shore et al., 2002; Wada et al., 2004). Using a 160-channel neuromagnetometer, one of two SOAs, either $100 \mathrm{~ms}$ (right-then-left, RL) or $-100 \mathrm{~ms}$ (left-then-right, LR), was randomly chosen for each trial. The median probability of judgment reversal was as large as 0.43 after the LR stimulation but decreased to 0.20 after the RL stimulation (Fig. 2c).

\section{Decomposition of the $\alpha$ rhythms}

Magnetic signals recorded from 160 squid sensors were combined across 16 participants and were decomposed into 12 ICs (group ICA), which were numbered in descending order of the power at $10 \mathrm{~Hz}$ (Fig. $3 a, b$ ). $\alpha$ rhythms were observed in each single trial in the first few ICs (Fig. $3 a$ ). Figure $3 c$ shows the distribution of the weights of each IC estimated for each of the 160 sensors. The weights for the first component were distributed bilaterally in the posterior region in a symmetrical manner with inverted signs in each hemisphere. The estimated cortical current dipoles (averaged across the brains of the 16 participants) were most apparent around the bilateral PO sulci, including the precuneus (Fig. $3 d$, 1: peri-PO component). The weights for the second component were distributed over the middle of the PO region (Fig. $3 c, 2$ ). The major cortical dipoles were estimated around its circular base, which included areas V2 and V3, which are close to the calcarine sulcus (2: Visual component, Fig. $3 d$ ) and the posterior part of the collateral sulci in the ventral region (data not shown). The major dipoles estimated for the third component were distributed in the bilateral primary auditory cortices with dominance on the left side (Fig. $3 d, 3$ ): we called this component the $\tau$ component in reference to the $\tau$ rhythm estimated in the auditory cortex (Tiihonen et al., 1991; Hari et al., 1997). The fourth and the fifth components yielded dipoles in the right and left Rolandic areas; we regarded them to be the equivalents of the $\mu$ rhythms (Fig. 3d, 4, 5: $\mu$-right, $\mu$-left). Thus, the $\alpha$ rhythms were successfully decomposed into five major statistically ICs, each of which approximately corresponded to its physiological counterpart in previous studies.

\section{Effects of the phase of the $\alpha$ rhythms on judgment reversal} ICA was further applied to the data for each individual participant. The peri-PO component was successfully decomposed for each participant (Fig. 4a). The correlation coefficients between the individual peri-PO components (Fig. $4 a$ ) and those of the group peri-PO component (Fig. $3 c, 1$ ) ranged from 0.68 to 0.98 . For each participant, the peri-PO component during a $1 \mathrm{~s}$ period
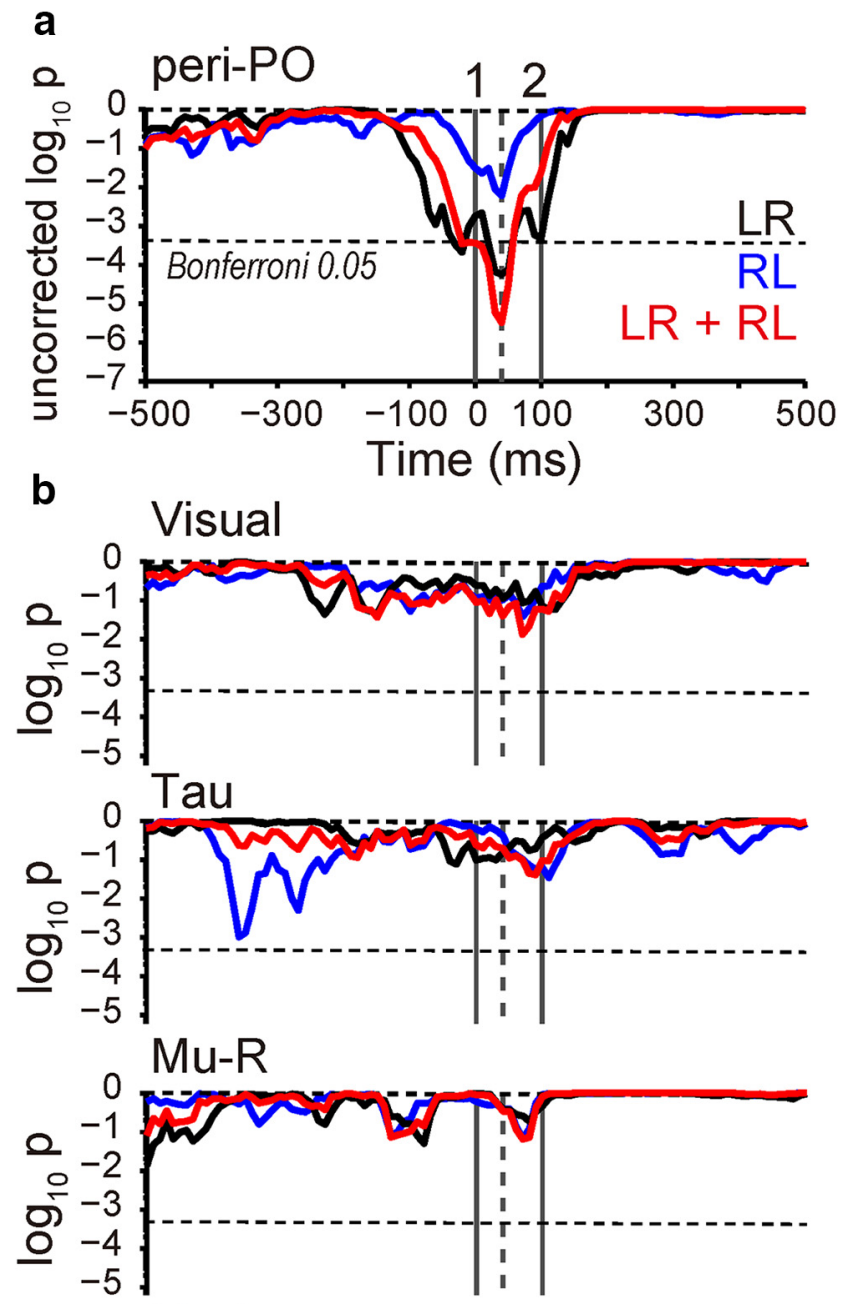

Mu-L

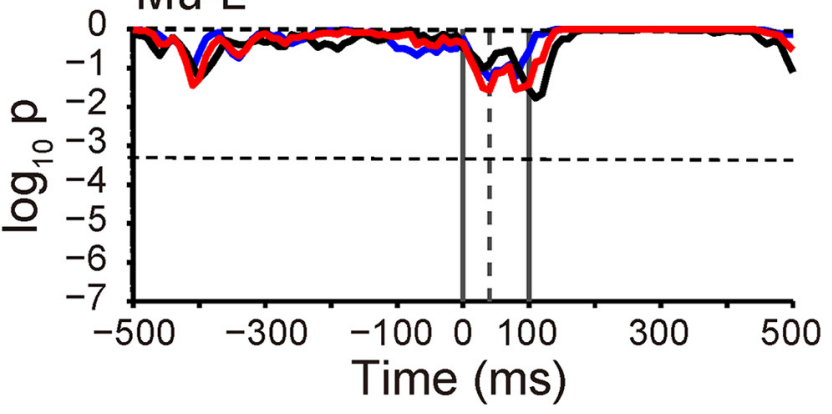

Figure 5. Comparison of phase differences in the 5 independent $\alpha$ rhythms. $\boldsymbol{a}$, The peri-P0 component. The $p$ value for the RL trials (blue) was less prominent than that for the LR trials (black) but reached the trough at the same time ( $40 \mathrm{~ms}$, vertical broken line). The uncorrected $p$ value became even smaller $\left(3.3 \times 10^{-6}\right)$ when both the LR and RL trials were combined. $\boldsymbol{b}$, The other 4 components. In marked contrast to the traces for the peri-P0 component, no other components showed significant phase differences after correction for the FDR $(0.05)$ at any moment during the peristimulus period.

around the LR stimulation was aligned to the stimulation onset and grouped according to whether the judgment was correct (blue) or inverted (red), as exemplified in Figure $4 b$ for a typical participant (No. 1). After subtracting the mean event-related field during a $200 \mathrm{~ms}$ period after the first L stimulus (thick horizontal line, top traces), it became obvious that the $10 \mathrm{~Hz}$ rhythms in the blue and red traces were out of phase during the peristimulus period. To objectively confirm this observation, we filtered subtracted traces (Fig. $4 b$, middle) within the band for the 
$\alpha$ rhythms (7-14 Hz), calculated the instantaneous phase for each trace, and compared the distributions of the instantaneous phases between the two judgment groups (inverted/correct) every $10 \mathrm{~ms}$ using the Watson-Williams test (Fig. 4b, bottom; see Materials and Methods). The uncorrected $p$ value was $<0.05$ during the peristimulus period $(-110,30 \mathrm{~ms})$.

The $p$ value was transformed into a $Z$ score (e.g., Fig. $4 c$, red trace, Participant 1 ) and summed over the 16 participants for a second-level analysis (Fig. 4c). The resulting $p$ values showed a sharp decrease $\sim 100$ ms before the onset of the first stimulus (left) and maintained significance $(p<0.05, \mathrm{FDR})$ from -70 to $110 \mathrm{~ms}$ with a trough at $40 \mathrm{~ms}$. The results show that the phase of the peri-PO $\alpha$ rhythm was different during the peristimulus period, according to whether the judgment was inverted.

We further examined whether the absolute phase for the correct (or for the inverted) judgment was shared across participants. We found that the mean individual phase for the correct judgment trials, or for the inverted judgment trials, at $40 \mathrm{~ms}$ was distributed in all directions among the 16 participants (Fig. $4 e$ ). However, when the individual "preferred" phase for the inverted judgment was adjusted to zero (Fig. $4 f$, right), the mean individual phase for the correct judgment was apparently distributed around the opposite direction $\left(\sim 180^{\circ}\right.$, Fig. $4 f$, left $)$. We also calculated the rate of correct judgment as a function of the $\alpha$ phase (12 30degree-wide bins, Fig. $4 g$ ). The mean correct judgment rate was smallest at the zero-degree bin $(0.49 \pm 0.05$, mean \pm SEM) and increased in the opposite direction where the mean correct judgment rate rose to $0.64 \pm 0.05$. The one-way ANOVA and post hoc tests (Ryan's method) showed that the phase-dependent modulation was significant $\left(F_{(11,165)}=4.1, p<0.0001\right)$.

We applied the same analyses to the data in the RL stimulation trials. The $p$ value showed a sharp decrease during the peristimulus period with a trough at 40 ms (Fig. $5 a$, blue trace) and the same timing as in the LR stimulation trials (black trace), although the $p$ value did not reach the level of significance after correction for the FDR. However, when we combined the $z$ values from the LR and RL stimulation trials, the trough uncorrected $p$ value decreased further to $3.3 \times 10^{-6}$ (red trace), which is smaller than that for the LR stimulation trials alone.

In marked contrast to the peri-PO component, the phase of the visual, $\tau, \mu$-right, and $\mu$-left components did not show any signifi-

\section{a}

b $n=16)$.
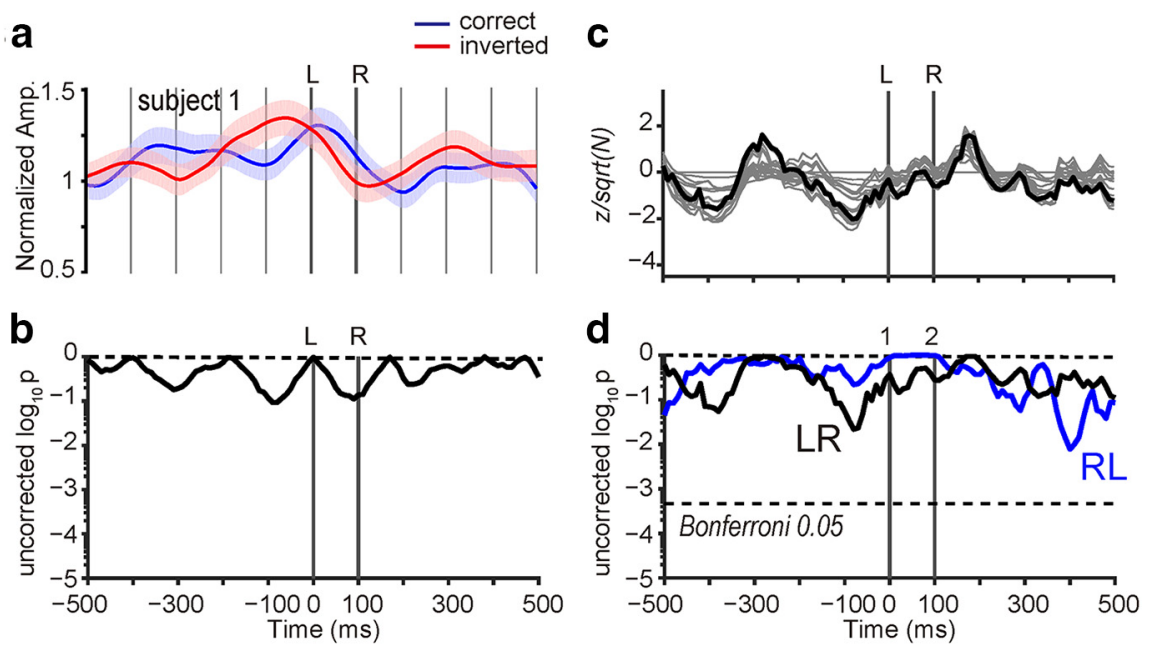

Figure 6. Effects of the amplitude of the peri-PO component on the tactile TOJ. $\boldsymbol{a}$, Comparison of the amplitudes of the peri-PO component between trials with correct judgment (blue) and those with inverted judgment (red) in one typical participant (№. 1 as in Fig. $4 b$ ) in the LR trials ( $n=47$ for correct and 53 for inverted judgment). Shaded areas represent the SEM. The traces are aligned at the onset of the first $L$ stimulus. $\boldsymbol{b}$, The $p$ values yielded by the Wilcoxon rank sum test used to compare the two amplitude distributions are shown. $\boldsymbol{c}, \boldsymbol{d}$, The second-level analysis for the peri-P0 component. Each uncorrected $p$ value was transformed into a $Z$ score and accumulated over the 16 participants (c). The intervals of the gray traces show the contributions from individual participants (c). The $p$ values yielded from the combined Stouffer's $Z$ score are plotted against the time from the first stimulus (d). The amplitude difference was not significant throughout the peristimulus period after correcting for the false discovery rate in the LR trials (black), or RL trials (blue).
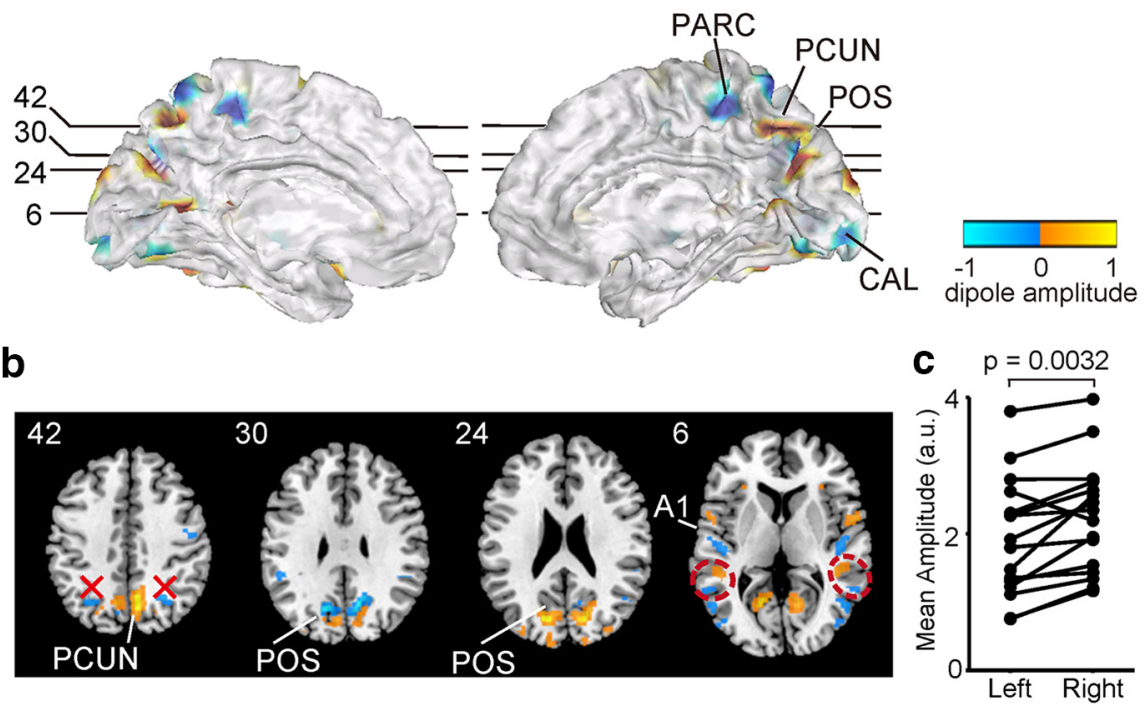

Figure 7. Distribution of cortical source currents estimated for the peri-P0 component (averaged over 16 participants). $\boldsymbol{a}$, Three-dimensional views through a transparent cortical surface: viewed from the right of the left hemisphere (left) and from the left of the right hemisphere (right). PARC, Paracentral cortex; PCUN, precuneus; POS, P0 sulcus; CAL, calcarine sulcus. Horizontal lines indicate the levels of the axial slices shown in $\boldsymbol{b}$. $\boldsymbol{b}$, Source currents are shown on axial slices that pass through the precuneus $(z=42), P 0$ sulcus ( 30 and 24$)$, and primary auditory cortex $(A 1,6)$. Red dotted circles $(z=6)$ represent regions implicated in the tactile TOJ task by representing multisensory apparent motion in space (adapted from Takahashi et al., 2013). $x$ signs $(z=42)$ show locations that have been implicated in the localization of tactile stimuli in space (Lloyd et al., 2003). Current sources were estimated within or close to these regions. c, Comparison of the mean estimated current sources in the left and the right hemispheres. Data pairs from each participant are connected with a line; note a significant right dominance (Wilcoxon signed rank test,

cant group differences after FDR correction at any time point during the peristimulus period for the LR stimulation (Fig. $5 b$, black traces), RL stimulation (blue traces), or both combined (LR+RL, red traces). 
a

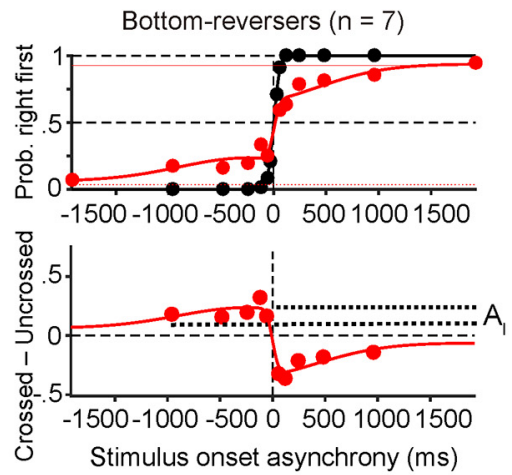

b

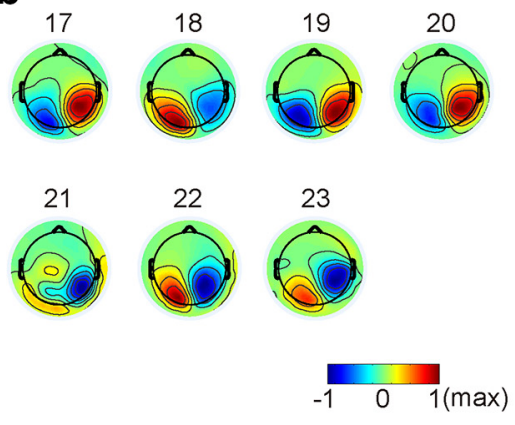

C
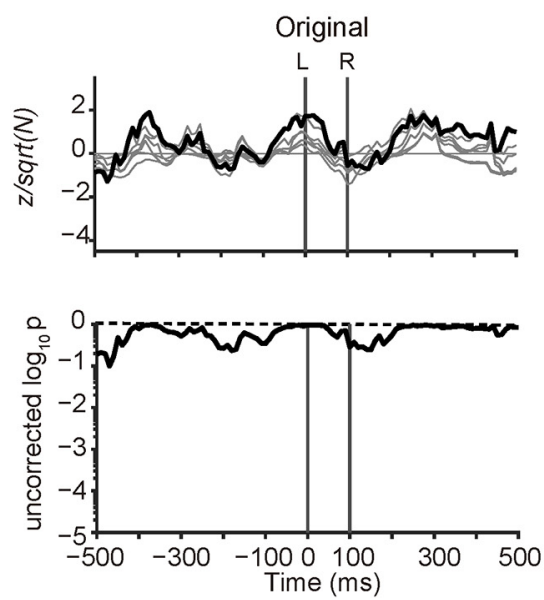

d
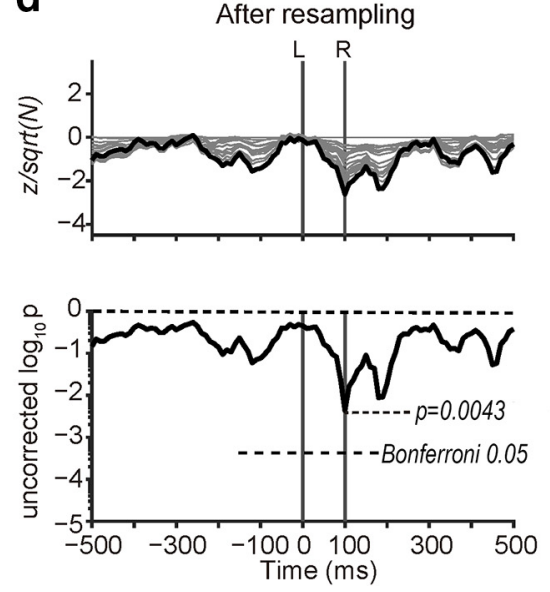

Figure 8. Effects of the phase of the peri-P0 component on 7 bottom-reversers with a smaller-than-median probability of judgment reversal. $\boldsymbol{a}$, The mean response profile of the participants in the screening experiments in the arms-crossed (red) and arms-uncrossed conditions (black). The probability of judgment reversal (bottom, peaks) was smaller than that for top-reversers shown in Figure $2 b . \boldsymbol{b}$, The spatial distribution of the peri-P0 component in the 7 participants; note the similarity with the top-reversers in Figure $4 a$. $c$, Results of the second-level analysis. When the Zscore was accumulated over the 7 participants (c, top), the $p$ values yielded from the combined Stouffer's $Z$ score did not achieve significance $(c$, bottom). Even when the number of participants and the probability of judgment reversal was corrected for that of the 16 top-reversers by using a resampling technique (d), Stouffer's $Z$ score did not reached the level of significance after the FDR or Bonferroni correction, but a trough appeared at $100 \mathrm{~ms}$ after onset of the first stimulus ( $p=0.0043$, uncorrected).

\section{Effects of the amplitude of the $\alpha$ rhythms on judgment reversal}

Next, we compared, for each participant, the instantaneous amplitude of each $\alpha$ component in trials with correct judgment with the amplitude in trials with inverted judgment trials (Fig. $6 a$, Participant 1). The amplitude of the peri-PO component of the exemplified participant (No. 1) did not show any significant difference at any time point during the peristimulus period for the LR stimulation (Fig. $6 b, p>0.05$, uncorrected). The second-level analyses, in which the $Z$ scores were summed across the 16 participants (Fig. $6 c$ ), yielded no significant differences in amplitude after the FDR correction (Fig. $6 d$, black trace). There were no significant differences in amplitude when the RL trials were analyzed (Fig. $6 d$, blue trace), or when the LR and RL trials were combined (data not shown). Similarly, there were no significant differences in any of the other four components.

\section{Cortical sources of the peri-PO component}

The peri-PO component was the only component the phase of which showed a significant correlation with the illusory perception of tactile temporal order. Thus, it is worth further examining the cortical sources of the peri-PO component. As previously shown in the group ICA analysis (Fig. $3 d$, 1: peri-PO), major current sources were located in regions near the PO sulcus, even when the current sources were estimated for each individual peri-PO component (Fig. $7 a$, an average of 16 participants). In addition, current sources were found over the primary auditory cortex as shown in the axial slice at $z=6$ (Fig. 7b). The widespread distribution suggested that the effect of the peri-PO component reached beyond the visual and tactile modalities, and the peri-PO component was consistently functioning regardless of whether the participants performed the tactile task.

When the sources (Fig. 7b) were compared with reported regions that were activated in response to the same tactile TOJ task, overlaps were found in the bilateral temporal regions (dotted circles on $z=6$, adapted from Takahashi et al., 2013). This region has been implicated in representing apparent motion signals generated by successive tactile signals or visual stimuli (Takahashi et al., 2013). In addition, sources were found in the ventral intraparietal regions ( $x$ signs on $z=42$ ) that have been implicated in the localization of tactile stimuli in space when the arm was crossed over the midline (Lloyd et al., 2003).

It is also worth noting that the estimated source currents were generally larger in the right hemisphere than in the left hemisphere (compare the left and right hemispheres in Fig. 7a). The right dominance of the peri-PO component was shown to be significant when the mean source current strengths in the right and left hemispheres were compared within the 16 participants $(p=0.0032$, Wilcoxon signed rank test; Fig. 7c).

\section{Generalizability to "bottom-reversers"}

Finally, we examined whether the current findings for the tophalf participants with a greater probability of judgment reversal could be generalized to the other half of participants with a smaller probability of judgment reversal (bottom-reversers). To address this issue, we collected MEG data from 7 bottom-reversers (Fig. 8). The mean response curve for the bottom-reversers in the arms crossed condition was no longer N-shaped (Fig. $8 a$, red trace), and the mean probability of judgment reversal in the MEG scanner dropped to 0.23 after LR stimulation. The same set of ICA analyses also identified the peri-PO component in the nonreversers (Fig. 8b). The second-level analyses revealed no significant phase differences between trials with correct judgment and those with inverted judgment when we simply summed the $Z$ scores from the 7 participants (Fig. $8 c$ ). The phase difference did not reach the level of significance, even after correcting for the difference in the number of participants ( 7 vs 16) and the rate of inverted judgment by using a 
bootstrap method (Fig. $8 d$ ). However, after bootstrapping, a trough appeared at $100 \mathrm{~ms}(p=0.0043$, uncorrected $)$ after the delivery of left hand stimulation, which was delayed compared with $40 \mathrm{~ms}$ in the top-reversers.

\section{Discussion}

We found that the probability of reversal of the subjective temporal order of two tactile stimuli (one delivered to each hand) depended on the phase of one IC that had strong $\alpha$-band signals and current sources located around the PO sulcus, which we named the peri-PO component. In contrast, the judgment did not depend on the phase of the other four ICs with $\alpha$-band activities, including the visual component with sources in V2 or other visual cortices, the right and left $\mu$ components in the Rolandic regions, or the $\tau$ component in the primary auditory cortex. The judgment did not depend on the amplitude of the five components. These results highlight the importance of the phase of the peri-PO $\alpha$ component in organizing temporospatial perception, not only in the visual but also in the tactile domain.

Notably, the tactile temporal order did not depend on the phase of the $\mu$ components, which were reported to have significant effects on the perception of tactile stimuli (Jones et al., 2010) and had been hypothesized to entrain the visual, auditory, and somatosensory centered $\alpha$ networks (Pineda, 2005). The lack of significant effects on TOJ brings into question the importance of the $\mu$ rhythms in entraining the entire $\alpha$ network. Indeed, two independent $\mu$ rhythms were decomposed in each hemisphere, clearly demonstrating that the effect of each $\mu$ rhythm is confined within a single hemisphere. This observation is consistent with previous findings that the $\mu$ rhythms in each hemisphere are not coherent (Pineda, 2005). Because of the lack of any significant effects on the tactile TOJ, we suggest that the effect of the $\mu$ rhythm is confined to the tactile modality and that the $\mu$ rhythm does not have power to entrain the entire $\alpha$ network (Fig. 9, $\mu$ ).

The peri-PO component yielded the largest power in the $\alpha$-band and was isolated in all 16 participants in the individual ICA (Fig. 4a). Estimated current sources were distributed in the upper and lower banks of the PO sulcus (Fig. 7a,b; $z=24, z=30$ ); the location was consistent with the single current dipole reported in previous studies for the posterior classical $\alpha$ rhythm (Hari et al., 1997; Vanni et al., 1997; van Dijk et al., 2008). By exploring the entire cerebral cortex, we found current sources in the bilateral precuneus (Fig. $7 a, b ; z=42$, PCUN) that were even stronger than those in the $\mathrm{PO}$ sulcus and the bilateral paracentral cortex (Fig. 7a; PARC). These regions exhibit several interesting features. First, nonretinotopic coordinates are represented. The human homolog of the macaque V6A, located along the PO sulcus (Pitzalis et al., 2013), may represent a craniotopic coordinate (Galletti et al., 1996). The exact region in the right precuneus represents an allocentric coordinate relative to the background (Uchimura et al., 2015). Second, these regions are multimodal; both visual and tactile signals converge in area V6A (Breveglieri et al., 2002). Third, according to recent network analyses, these regions, the precuneus and paracentral cortex in particular, constitute central hubs in the entire cortical network (Hagmann et al., 2008). In agreement with the hub idea, the estimated current sources extended beyond the core hub regions to the primary auditory cortex (Fig. $7 b ; z=6$ ), the bilateral temporal regions (dotted circles, $z=6$ ), and the ventral intraparietal regions ( $x$ signs, $z=42$ ).

Bearing these remarkable features of the peri-PO component in mind, let us return to the initial schema (Fig. 1), in which tactile signals were supposed to interact with the posterior $\alpha$

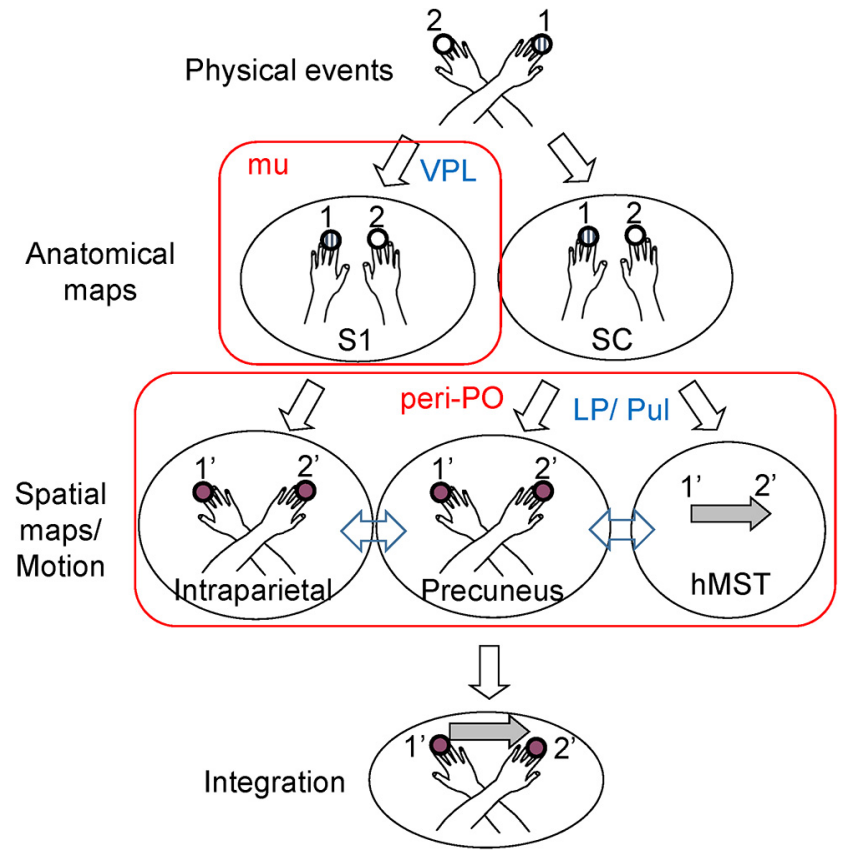

Figure 9. Suggested sites of interaction between the $\alpha$ rhythms and the proposed processes of illusory reversal in subjective temporal order due to arm crossing. The $\mu$ components, which would phasically modulate signal transmission in the VPL nucleus, did not affect illusory reversal. By contrast, the peri-PO component, the current sources of which were located mainly in the precuneus and distributed over the intraparietal regions and motion-related areas, affected the probability of judgment reversal. We suggest that the peri-PO component plays an essential role in regulating tactile temporal perception by modulating the thalamic nuclei (LP/Pul) that interconnect the superior colliculus (SC) with the cortical networks. Numbers indicate two stimuli delivered first to the left hand (1) and then to the right hand (2). ${ }^{\prime}$ and $2^{\prime}$ indicate erroneous direct mappings to the spatial or motion maps (intraparietal, precuneus, and hMST) from the anatomical maps. The enhanced "direct" mappings would eventually lead to the inverted judgment $\left(1^{\prime}\right.$ and $\left.2^{\prime}\right)$. VPL, Ventral posterolateral nucleus of the thalamus; LP, lateral posterior nucleus; Pul, pulvinar; S1, primary somatosensory cortex; hMST, human homolog of the macaque medial superior temporal area.

rhythm either in the spatial map or in the area of motion. The present results do not exclude either possibility because the estimated sources of the peri-PO component were distributed over the bilateral temporal regions (Fig. $7 b$, dotted circles) that have been implicated in representing apparent motion signals (Takahashi et al., 2013) and in the ventral intraparietal regions ( $x$ signs on $z=42$ ) that have been implicated in localizing tactile stimuli in space when the arm was crossed (Lloyd et al., 2003). Further, we were able to raise the precuneus as a candidate region of interaction because this area receives tactile inputs and represents spatial coordinates (Uchimura et al., 2015; Galletti et al., 1996). Thus, there are at least three candidate regions in which tactile signals would interact with the peri-PO component (Fig. 9; intraparietal, precuneus, and human homolog of the macaque medial superior temporal area).

We then question whether the latency of $40 \mathrm{~ms}$, at which time the effect of the peri-PO component was maximized, would be sufficient for the tactile signals to reach the three regions. According to Avillac et al. (2007), 60\% of neurons in the macaque ventral intraparietal area (VIP) responded within $35 \mathrm{~ms}$ to tactile stimuli to the face, and $20 \%$ of the neurons responded within $20 \mathrm{~ms}$ (Avillac et al., 2007, their Fig. 4). It has also been reported that many neurons in the middle intraparietal area, which is adjacent to the VIP, receives tactile inputs from the hand (Colby and Duhamel, 1991). Thus, it is reasonable to expect that the first tactile signals from the hand could reach the human homolog of the 
macaque intraparietal areas within $40 \mathrm{~ms}$, even if we assume a conduction delay of $20 \mathrm{~ms}$ for traveling the additional distance of the human arm length $(\sim 1 \mathrm{~m})$ at $50 \mathrm{~m} / \mathrm{s}$. Next, we examine the second candidate, the precuneus, to which belongs the human homolog of area V6A. Macaque V6A has been reported to receive tactile inputs from the hand (Breveglieri et al., 2002), at least a portion of which are conveyed through direct projection from the lateral parietal nucleus of the thalamus (Gamberini et al., 2016). Because the lateral parietal nucleus receives projections from the superior colliculus that respond to tactile stimuli to the forelimb of the cat with a latency smaller than $20 \mathrm{~ms}$ (Abrahams et al., 1988), the tactile signals should be able to reach the precuneus well within $40 \mathrm{~ms}$ via the tecto-thalamic pathway (Fig. 9). Finally, we turn to human MT/MST (Takahashi et al., 2013). A recent human $\mathrm{fMRI}$ study confirmed that this region, which has been identified as the human homolog of MST, responds to tactile stimulation delivered to the hands (Beauchamp et al., 2007). One candidate source that delivers the tactile inputs to MST is the VIP (Beauchamp et al., 2007). Another candidate is the pulvinar, which is reciprocally connected to MST (Boussaoud et al., 1992). Because the pulvinar receives direct projections from the superior colliculus, it is likewise possible that MST neurons respond within $40 \mathrm{~ms}$ via the tectopulvinar pathway (Fig. 9). In conclusion, all three candidate regions can potentially be activated within $40 \mathrm{~ms}$ after delivery of a tactile stimulus to the hand.

It is generally accepted that a stimulus to one of the two crossed hands is initially mapped to the wrong hand, or its anatomical location, and then remapped to the correct hand, or integrated with the spatial hand position, thereafter (Kitazawa, 2002; Azañón and Soto-Faraco, 2008; Heed and Azañón, 2014; Heed et al., 2015). The initial erroneous mapping can be considered an emphasis on the anatomical or somatotopic representation (Heed and Azañón, 2014; Heed et al., 2015), which can be represented in the primary sensory cortex (Fig. 9, S1) and the superior colliculus. It is possible that the peri-PO component enhanced "direct" mappings from these anatomical maps (No. 1 in S1 and superior colliculus; Fig. 9) to the spatial or motion maps (No. $1^{\prime}$ in intraparietal, precuneus, and human homolog of the macaque medial superior temporal area) in one phase and suppressed the direct mapping in the opposite phase. Recent studies have shown that $\alpha$ rhythms generally act upon the sensory thalamus or the pulvinar such that information transmission through the thalamus or pulvinar is regulated at $10 \mathrm{~Hz}$ (Lorincz et al., 2009; Saalmann et al., 2012). By analogy, it is reasonable to assume that the peri-PO component acted on the lateral parietal nucleus or the pulvinar such that the anatomical mapping from the superior colliculus was periodically enhanced at $10 \mathrm{~Hz}$. Because the precuneus occupies a central hub region in cortical networks and represents allocentric spatial coordinates, we finally suggest that the peri-PO component plays an essential role in regulating tactile spatiotemporal perception by modulating the thalamic nuclei that interconnect the superior colliculus to the cortical networks at $10 \mathrm{~Hz}$.

In our first report of the illusory reversal of temporal order (Yamamoto and Kitazawa, 2001), we inferred that intersubject variability may result from varying degrees of active preparation for remapping from the "default" anatomical position to the "correct" spatial location. Under this assumption, bottom-reversers could have depended less on the tecto-thalamo-cortical pathways that simply convey the initial "anatomical" mapping. The phasic effect of the peri-PO $\alpha$ on the lateral-posterior pulvinar complex in the thalamus should then be minimized in the bottomreversers. Indeed, we have shown that this appears to be the case: the peri-PO phase effect on judgment was smaller and delayed in "bottom-reversers" (Fig. 8). Whether top- and bottom-reversers depend differently on the tecto-thalamo-cortical pathway and whether the tecto-thalamo-cortical pathway is actually modulated by the peri-PO component merit further investigation.

\section{References}

Abrahams VC, Clinton RJ, Downey D (1988) Somatosensory projections to the superior colliculus of the anaesthetized cat. J Physiol 396:563-580. CrossRef Medline

Avillac M, Ben Hamed S, Duhamel JR (2007) Multisensory integration in the ventral intraparietal area of the macaque monkey. J Neurosci 27:1922_ 1932. CrossRef Medline

Azañón E, Soto-Faraco S (2008) Changing reference frames during the encoding of tactile events. Curr Biol 18:1044-1049. CrossRef Medline

Badde S, Heed T, Röder B (2014) Processing load impairs coordinate integration for the localization of touch. Atten Percept Psychophys 76:11361150. CrossRef Medline

Beauchamp MS, Yasar NE, Kishan N, Ro T (2007) Human MST but not MT responds to tactile stimulation. J Neurosci 27:8261-8267. CrossRef Medline

Berens P (2009) CircStat: a MATLAB toolbox for circular statistics. J Stat Softw 31:1-21.

Boussaoud D, Desimone R, Ungerleider LG (1992) Subcortical connections of visual areas MST and FST in macaques. Vis Neurosci 9:291-302. CrossRef Medline

Breveglieri R, Kutz DF, Fattori P, Gamberini M, Galletti C (2002) Somatosensory cells in the parieto-occipital area V6A of the macaque. Neuroreport 13:2113-2116. CrossRef Medline

Busch NA, Dubois J, VanRullen R (2009) The phase of ongoing EEG oscillations predicts visual perception. J Neurosci 29:7869-7876. CrossRef Medline

Colby CL, Duhamel JR (1991) Heterogeneity of extrastriate visual areas and multiple parietal areas in the macaque monkey. Neuropsychologia 29: 517-537. CrossRef Medline

Delorme A, Makeig S (2004) EEGLAB: an open source toolbox for analysis of single-trial EEG dynamics including independent component analysis. J Neurosci Methods 134:9-21. CrossRef Medline

Dugué L, Marque P, VanRullen R (2011) The phase of ongoing oscillations mediates the causal relation between brain excitation and visual perception. J Neurosci 31:11889-11893. CrossRef Medline

Friston K, Harrison L, Daunizeau J, Kiebel S, Phillips C, Trujillo-Barreto N, Henson R, Flandin G, Mattout J (2008) Multiple sparse priors for the M/EEG inverse problem. Neuroimage 39:1104-1120. CrossRef Medline

Galletti C, Fattori P, Battaglini PP, Shipp S, Zeki S (1996) Functional demarcation of a border between areas $\mathrm{V} 6$ and $\mathrm{V} 6 \mathrm{~A}$ in the superior parietal gyrus of the macaque monkey. Eur J Neurosci 8:30-52. CrossRef Medline

Gamberini M, Bakola S, Passarelli L, Burman KJ, Rosa MG, Fattori P, Galletti C (2016) Thalamic projections to visual and visuomotor areas (V6 and V6A) in the Rostral Bank of the parieto-occipital sulcus of the Macaque. Brain Struct Funct 221:1573-1589. CrossRef Medline

Hagmann P, Cammoun L, Gigandet X, Meuli R, Honey CJ, Wedeen VJ, Sporns O (2008) Mapping the structural core of human cerebral cortex. PLoS Biol 6:e159. CrossRef Medline

Hari R, Salmelin R, Mäkelä JP, Salenius S, Helle M (1997) Magnetoencephalographic cortical rhythms. Int J Psychophysiol 26:51-62. CrossRef Medline

Heed T, Azañón E (2014) Using time to investigate space: a review of tactile temporal order judgments as a window onto spatial processing in touch. Front Psychol 5:76. CrossRef Medline

Heed T, Buchholz VN, Engel AK, Röder B (2015) Tactile remapping: from coordinate transformation to integration in sensorimotor processing. Trends Cogn Sci 19:251-258. CrossRef Medline

Hyvarinen A, Oja E (1997) A fast fixed-point algorithm for independent component analysis. Neural Comput 9:1483-1492. CrossRef

Jones SR, Kerr CE, Wan Q, Pritchett DL, Hämäläinen M, Moore CI (2010) Cued spatial attention drives functionally relevant modulation of the mu rhythm in primary somatosensory cortex. J Neurosci 30:13760-13765. CrossRef Medline

Kitazawa S (2002) Where conscious sensation takes place. Conscious Cogn 11:475-477. CrossRef Medline

Kitazawa S, Moizumi S, Okuzumi A, Saito F, Shibuya S, Takahashi T, Wada 
M, Yamamoto S (2007) Reversal of subjective temporal order due to sensory and motor integrations. In: Attention and performance, Vol XXII (Haggard P, Kawato M, Rossetti Y, eds), pp 73-97. Oxford: Oxford UP.

Kristofferson AB (1967) Successiveness discrimination as a two-state, quantal process. Science 158:1337-1339. CrossRef Medline

Lloyd DM, Shore DI, Spence C, Calvert GA (2003) Multisensory representation of limb position in human premotor cortex. Nat Neurosci 6:17-18. CrossRef Medline

López JD, Litvak V, Espinosa JJ, Friston K, Barnes GR (2014) Algorithmic procedures for Bayesian MEG/EEG source reconstruction in SPM. Neuroimage 84:476-487. CrossRef Medline

Lorincz ML, Kékesi KA, Juhász G, Crunelli V, Hughes SW (2009) Temporal framing of thalamic relay-mode firing by phasic inhibition during the alpha rhythm. Neuron 63:683-696. CrossRef Medline

Mathewson KE, Gratton G, Fabiani M, Beck DM, Ro T (2009) To see or not to see: prestimulus alpha phase predicts visual awareness. J Neurosci 29: 2725-2732. CrossRef Medline

Niedermeyer E (1997) Alpha rhythms as physiological and abnormal phenomena. Int J Psychophysiol 26:31-49. CrossRef Medline

Nishikawa N, Shimo Y, Wada M, Hattori N, Kitazawa S (2015) Effects of aging and idiopathic Parkinson's disease on tactile temporal order judgment. PLoS One 10:e0118331. CrossRef Medline

Oldfield RC (1971) The assessment and analysis of handedness: the Edinburgh Inventory. Neuropsychologia 9:97-113. CrossRef Medline

Palva S, Palva JM (2011) Functional roles of alpha-band phase synchronization in local and large-scale cortical networks. Front Psychol 2:204. CrossRef Medline

Pineda JA (2005) The functional significance of mu rhythms: translating "seeing" and "hearing" into "doing." Brain Res Rev 50:57-68. CrossRef Medline

Pitzalis S, Sereno MI, Committeri G, Fattori P, Galati G, Tosoni A, Galletti C (2013) The human homologue of macaque area V6A. Neuroimage 82: 517-530. CrossRef Medline

Rorden C, Karnath HO, Bonilha L (2007) Improving lesion-symptom mapping. J Cogn Neurosci 19:1081-1088. CrossRef Medline

Rousseeuw PJ (1987) Silhouettes: a graphical aid to the interpretation and validation of cluster analysis. J Comput Appl Math 20:53-65. CrossRef

Ruzzoli M, Soto-Faraco S (2014) Alpha stimulation of the human parietal cortex attunes tactile perception to external space. Curr Biol 24:329-332. CrossRef Medline
Saalmann YB, Pinsk MA, Wang L, Li X, Kastner S (2012) The pulvinar regulates information transmission between cortical areas based on attention demands. Science 337:753-756. CrossRef Medline

Schubert JT, Buchholz VN, Föcker J, Engel AK, Röder B, Heed T (2015) Oscillatory activity reflects differential use of spatial reference frames by sighted and blind individuals in tactile attention. Neuroimage 117:417428. CrossRef Medline

Shore DI, Spry E, Spence C (2002) Confusing the mind by crossing the hands. Brain Res Cogn Brain Res 14:153-163. CrossRef Medline

Sokoliuk R, VanRullen R (2013) The flickering wheel illusion: when alpha rhythms make a static wheel flicker. J Neurosci 33:13498-13504. CrossRef Medline

Stouffer SA, Suchman EA, DeVinney LC, Star SA, Williams RMJ (1949) Adjustment during Army life. Princeton, NJ: Princeton UP.

Takahashi T, Kansaku K, Wada M, Shibuya S, Kitazawa S (2013) Neural correlates of tactile temporal-order judgment in humans: an fMRI study. Cereb Cortex 23:1952-1964. CrossRef Medline

Tiihonen J, Hari R, Kajola M, Karhu J, Ahlfors S, Tissari S (1991) Magnetoencephalographic $10-\mathrm{Hz}$ rhythm from the human auditory cortex. Neurosci Lett 129:303-305. CrossRef Medline

Uchimura M, Nakano T, Morito Y, Ando H, Kitazawa S (2015) Automatic representation of a visual stimulus relative to a background in the right precuneus. Eur J Neurosci 42:1651-1659. CrossRef Medline

van Dijk H, Schoffelen JM, Oostenveld R, Jensen O (2008) Prestimulus oscillatory activity in the alpha band predicts visual discrimination ability. J Neurosci 28:1816-1823. CrossRef Medline

van Ede F, de Lange F, Jensen O, Maris E (2011) Orienting attention to an upcoming tactile event involves a spatially and temporally specific modulation of sensorimotor alpha- and beta-band oscillations. J Neurosci 31:2016-2024. CrossRef Medline

Vanni S, Revonsuo A, Hari R (1997) Modulation of the parieto-occipital alpha rhythm during object detection. J Neurosci 17:7141-7147. Medline

Varela FJ, Toro A, John ER, Schwartz EL (1981) Perceptual framing and cortical alpha rhythm. Neuropsychologia 19:675-686. CrossRef Medline

Wada M, Yamamoto S, Kitazawa S (2004) Effects of handedness on tactile temporal order judgment. Neuropsychologia 42:1887-1895. CrossRef Medline

Yamamoto S, Kitazawa S (2001) Reversal of subjective temporal order due to arm crossing. Nat Neurosci 4:759-765. CrossRef Medline 